\title{
RESEARCH
}

Open Access

\section{Elucidation of the levels of vitamin $D$, calcium, and magnesium in the serum of Egyptian migraine patients: a case-control study}

Dorreya A. Elsayed ${ }^{1}$, Karam S. Amin ${ }^{1}$, Ibrahim A. Elsayed ${ }^{2}$ and Noha A. Hashim ${ }^{*^{*}}$ (1)

\begin{abstract}
Background: Migraine, although, is a prevalent disease; its pathogenesis is complex and still not fully elucidated. The effect of vitamin D on various neurological disorders is thought to be exerted either directly via its specific receptors or through the related minerals. We investigated the possible relationship between vitamin $\mathrm{D}$ level and its related minerals (calcium and magnesium) and migraine characteristics in patients.

Subjects and methods: Thirty healthy individuals and 60 age- and sex-matched migraineurs (22 chronic and 38 episodic migraineurs), diagnosed according to the International Headache Society criteria (ICHD-III), were recruited. After obtaining basic data, a visual analogue scale (VAS) for the severity of migraine pain was assessed. Migraine severity questionnaire (MIGSEV) and the Migraine Disability Assessment (MIDAS) questionnaire were given and illustrated to the participants. Blood samples were obtained, and serum concentrations of vitamin D, calcium, and magnesium were determined.

Results: Migraine patients had significantly lower level of serum vitamin D and magnesium than healthy subjects with $(P<0.001$ and $P=0.04)$, respectively. However, the difference between the serum calcium levels of the patient and the control group was not statistically significant. Moreover, vitamin D and magnesium had a significant negative correlation with frequency, duration, severity, and disability in migraine.

Conclusion: Vitamin D and magnesium were significantly deficient in migraine patients and were related to the severity and disability of migraine attacks. Low vitamin $D$ and magnesium levels were associated with more frequency and longer duration of migraine attacks.
\end{abstract}

Keywords: Migraine, Vitamin D, Magnesium, Pain, Disability

\section{Introduction}

Migraine is one of the most common disabling neurological disorders. It is characterized by recurrent episodes of headache, variable in duration, intensity, and frequency, and is accompanied by nausea, vomiting, photophobia, and/or phonophobia. In some cases, migraine attacks are preceded by focal neurological symptoms called aura [1].

\footnotetext{
*Correspondence: n.hashim83@hotmail.com

'Department of Neurology, Faculty of Medicine, Zagazig University, Zagazig, Egypt

Full list of author information is available at the end of the article
}

Although the diagnosis of migraine remains mostly clinical, researchers have made great efforts in the investigation of the role of the neurotransmitter, hormones, and other biochemical elements in the pathophysiology of this disease. Such efforts have permitted a better understanding of the cerebral and extra-neurological mechanisms underlying this type of headache leading to the identification of a treatment target [2].

Vitamin D has been suggested to play an important role in various physiological activities such as immune system regulation and resolution of inflammation, which 
are both proposed to be involved in the pathogenesis of several neurological diseases including migraine [3].

Among all the serum electrolytes, magnesium plays a significant role in the conversion of vitamin D by hepatic 25 -hydroxylation and renal 1 $\alpha$-hydroxylation into the active, hormonal form 1,25-dihydroxy-vitamin D [4]. Magnesium deficiency results in reduced levels of vitamin $\mathrm{D}$ and impaired parathyroid hormone response [5]. Magnesium supplementation was shown to markedly reduce the resistance to vitamin $\mathrm{D}$ treatment, and it has been implicated in magnesium-dependent vitamin D-resistant rickets. It also plays a key role in bone mineralization by influencing synthesis of the active vitamin D metabolites [6]. Magnesium deficiency is found in patients with chronic medical illnesses, including cardiovascular disease, diabetes, pre-eclampsia, eclampsia, sickle cell disease, and chronic alcoholism [7]. Henceforth, we investigated the impact of vitamin D and its related minerals (calcium and magnesium) on migraine characteristics.

\section{Methods}

This case-control study was carried out over a period of 6 months from July 2018 to December 2018, on 78 migraine patients, diagnosed according to the international classification of headache disorders, third edition (ICHD-3) [8]. The exclusion criteria were age $<18$ years, patients with known history of other neurological diseases (cerebrovascular stroke, epilepsy, brain tumors, multiple sclerosis), those who have received vitamin $\mathrm{D}$ supplements in the previous 4 months, those with concomitant medical diseases especially tumors, hypertension, diabetes, renal or hepatic insufficiency, autoimmune disease, and thyroid diseases, and the patients on medications that clearly affect electrolytes' levels such as diuretics, cyclosporine, aminoglycosides, and acetazolamide. Eighteen patients were excluded, leaving a sample of 60 patients; they were $40(66.6 \%)$ females and $20(33.3 \%)$ males, with an age range of (19-49) years and a mean age of $31.13 \pm 7.4$ years. Apparently, 30 healthy individuals, 12 (40\%) males, and 18 (18\%) females, matched for age, gender, and menstrual status of the female patients, were served as a control group. The characteristics of the patients and control are summarized in (Table 1).

The detailed history of all migraine patients including, level of education, residence, and consumption of vitamin and mineral supplements was collected. General and neurological examinations and the assessment of migraine characteristics using the visual analogue score for pain intensity [9] were conducted. Migraine severity was assessed by the Migraine Severity Scale (MIGSEV) [10] and the Migraine Disability Assessment (MIDAS) questionnaires to evaluate the migraine-related disability in different life domains of the patients over the previous 3 months.

The venous blood samples $(5 \mathrm{~mL})$ were collected under complete aseptic conditions from all the subjects included in the present study. A fresh serum aliquot for each subject was used for the assay of electrolytes including serum calcium and magnesium, liver, and kidney functions. Regarding vitamin $\mathrm{D}$, blood samples were collected, centrifuged, and stored at $-80^{\circ} \mathrm{C}$. Serum levels of vitamin D were measured using the enzyme-linked immunosorbent assay (ELISA) method. Vitamin D insufficiency was noted at $20-29 \mathrm{ng} / \mathrm{mL}$ and vitamin D deficiency at $<20 \mathrm{ng} / \mathrm{mL}$ [11]. Repeated freezing and thawing cycles were avoided.

Table 1 Demographic characteristics of migraine patients and control subjects

\begin{tabular}{|c|c|c|c|c|}
\hline & & Migraine (60 patients) & Control (30 subjects) & $p$ value \\
\hline & & $N(\%)$ & $N(\%)$ & \\
\hline Age (mean \pm SD) & & (19-49) $31.13 \pm 7.4$ & $(21-50) 31.56 \pm 7.6$ & 0.1 \\
\hline BMI (mean \pm SD) & & $28.8 \pm 5.9$ & $30.2 \pm 4.6$ & 0.1 \\
\hline \multirow[t]{2}{*}{ Residence } & Urban & $34(56.7 \%)$ & $22(73.3 \%)$ & \multirow[t]{2}{*}{0.1} \\
\hline & Rural & $26(43.3 \%)$ & $8(26.6 \%)$ & \\
\hline \multirow[t]{2}{*}{ Gender } & Female & $40(66.7 \%)$ & $18(60.0 \%)$ & \multirow[t]{2}{*}{0.7} \\
\hline & Male & 20 (33.3\%) & $12(40.0 \%)$ & \\
\hline \multirow[t]{2}{*}{ Education } & Higher (> 12 years) & 44 (73.3\%) & $18(60.0 \%)$ & \multirow[t]{2}{*}{0.2} \\
\hline & Basic ( $\leq 12$ years) & $16(26.7 \%)$ & $12(40.0 \%)$ & \\
\hline \multirow[t]{2}{*}{ Smoking } & Yes & $8(13.3 \%)$ & 7 (23.4\%) & \multirow[t]{2}{*}{0.1} \\
\hline & No & $52(86.7 \%)$ & $23(76.6 \%)$ & \\
\hline \multirow[t]{2}{*}{ Marital status } & Single & $18(30.0 \%)$ & $13(43.3 \%)$ & \multirow[t]{2}{*}{0.21} \\
\hline & Married & $42(70.0 \%)$ & $17(56.7 \%)$ & \\
\hline \multirow{2}{*}{$\begin{array}{l}\text { Oral contraceptive pills } \\
\text { (in married females) }\end{array}$} & Yes & $5(23.8 \%)$ & $3(33.3 \%)$ & \multirow[t]{2}{*}{0.1} \\
\hline & No & $21(76.2 \%)$ & $9(66.7 \%)$ & \\
\hline
\end{tabular}

Continuous data are represented as mean \pm SD; categorical data are represented as number and percentage $N$ number, $\%$ percentage, $M \pm S D$ mean \pm standard deviation 


\section{Statistical analysis}

The collected data were coded, entered, presented, and analyzed by a computer using a database software program, Statistical Package for Social Science (SPSS) version 22 [12]. Quantitative variables were expressed as the mean $\pm \mathrm{SD}$ and range, and the categorical variables were expressed as a number and percentage. Continuous data were checked for normality by using the ShapiroWilk test. Student's $t$ test was used to compare two independent groups of normally distributed data, while the Mann-Whitney $U$ test was used for non-normally distributed data. The percentages of categorical variables were compared using the chi-square test. Spearman's rank correlation analysis was done between the selected study parameters. $P$ value $<0.05$ was considered statistically significant.

Our institutional review boards approved this study, and informed consent was obtained from each patient before starting the study.

\section{Results}

Among the study participants who suffered from migraine, 38 patients $(63.3 \%)$ were diagnosed with episodic migraine (EM), whereas $22(36.7 \%)$ with chronic migraine $(\mathrm{CM})$. Only ten patients (16.7\%) experienced symptoms consistent with the diagnosis of migraine with aura; on the contrary, 50 (83.3\%) patients had migraine without aura (Fig. 1). The age of onset of the disease ranged from 10 to 35 years of age, with a mean of $25.9 \pm$ 5.5 years, and the whole duration of illness ranged from 1 to 19 years with a mean of $5.2 \pm 5.1$ years. While the frequency of attacks for the last month ranged from 4 to 30 with a mean of $14.37 \pm 7.75$, the average duration of a headache attack was about $12 \mathrm{~h}$ with a mean of 11.43 $\pm 7.04 \mathrm{~h}$. The intensity of migraine headache pain on the
VAS ranged from 2 to 9 with a mean of $6.30 \pm 1.90$ (Table 2). The severity of migraine was assessed by the migraine severity questionnaire (MIGSEV) and results showed that $43.3 \%$ (26 patients) had grade 1 (low) severe headache, and 16.7\% (10 patients) suffered grade 3 (high) severity, with the rest of the patients (40\%) were in the intermediate severity grade 2 . The level of impairment in daily activities, as assessed by the Migraine Disability Assessment (MIDAS) questionnaire, indicated that 26.7\% of the patients were associated with little or no disability, $46.7 \%$ with mild disability, $23.3 \%$ with moderate disability, and only $3.3 \%$ with severe disability (Table 3 ). The statistical analysis evaluated the mean $( \pm S D)$ level of vitamin $\mathrm{D}$ to be significantly higher in the control group (27.23 \pm $7.65)$ as compared to the migraines' group $(16.77 \pm 7.47)$ with $P<0.001$. Vitamin D deficiency among migraine patients was $60 \%$ (36 patients), and insufficiency was 33.3\% (20 patients), whereas only $6.7 \%$ (4 patients) had normal levels. While $43 \%$ of participants of the control group had normal vitamin D levels, and 13\% of them had deficient levels, $43 \%$ of healthy individuals also had vitamin D insufficiency (Fig. 2).

Serum magnesium was significantly higher in the control group $(2.21 \pm 0.40 \mathrm{mEq} / \mathrm{L})$ than the patient's group $(1.88 \pm 0.20 \mathrm{mEq} / \mathrm{L})(p=0.04)$. On the contrary, the calcium level reported no significant difference between the two groups $(p=0.62)$. Other basic laboratory investigations showed no statistically significant differences between both the groups (Table 4).

Vitamin D level and calcium were significantly lower ( $p=0.002$ and $p<0.05$, respectively) in patients of migraine without aura compared to patients having migraine with aura. However, there was no statistical difference between the two groups regarding magnesium level $(p=$ 0.11 ). According to the type of migraine, vitamin D and

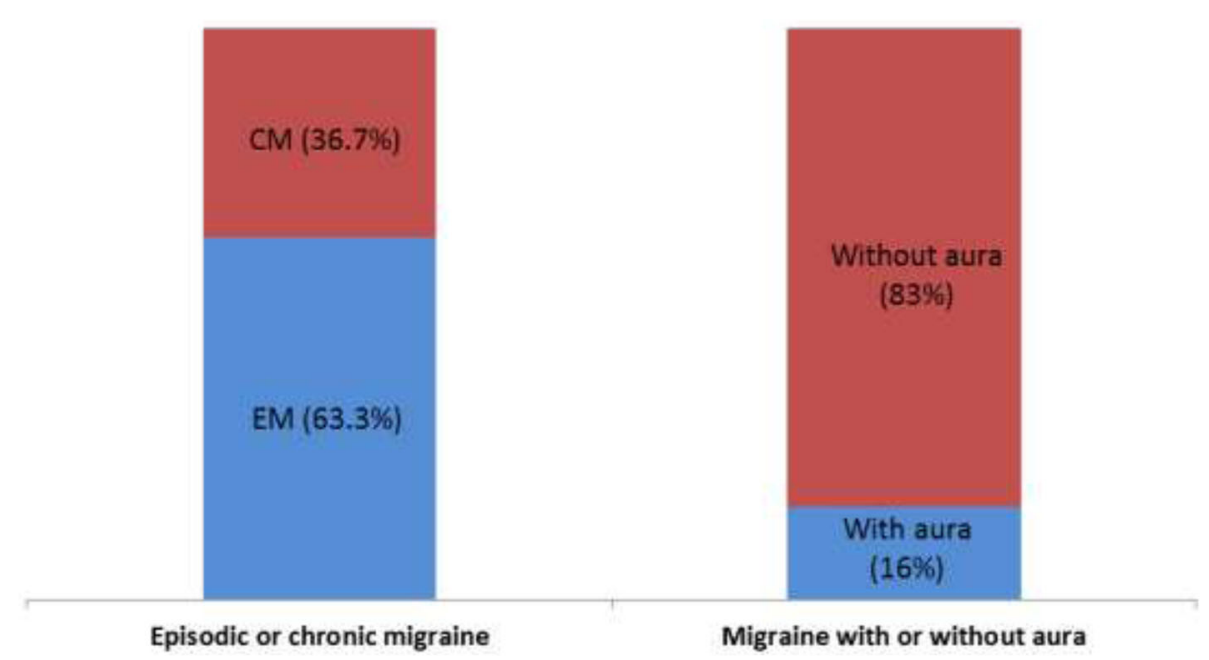

Fig. 1 Sub-groups of migraine patients 
Table 2 Clinical characteristics of migraine attacks

\begin{tabular}{lllll}
\hline Migraine group & Mean $( \pm$ SD $)$ & Median & Minimum & 10 \\
\hline Age of onset & $25.9( \pm 5.5)$ & 26.5 & 1 & 35 \\
Duration of illness (/years) & $5.2( \pm 5.1)$ & 4 & 3.00 & 19 \\
Attack duration (/hours) & $11.43( \pm 7.04)$ & 12.00 & 4.00 & 24.00 \\
$\begin{array}{l}\text { Frequency of attacks } \\
\text { (per month) }\end{array}$ & $14.37( \pm 7.75)$ & 12.00 & 2.00 & 30.00 \\
Pain intensity on VAS & $6.30( \pm 1.90)$ & 6.00 & 9.00 \\
\hline
\end{tabular}

SD standard deviation, VAS visual analog scale

serum magnesium were higher in patients with episodic migraine $(\mathrm{EP})$ than patients with chronic migraine $(\mathrm{CM})$ with a statistically significant difference between two groups $(p<0.001$ and $p=0.04$ respectively). However, there was no statistical difference between the two types of migraine regarding serum calcium level $(p=0.12)$. When we compared serum level of vitamin D, calcium, and magnesium in patients taking prophylactic migraine medications and the other group of patients without any prophylaxis treatment, we found no significant difference between the two groups of patients (Table 5).
Both vitamin D and serum magnesium showed statistically significant negative correlation with body mass index (BMI) $(p<0.001$ and $p=0.017)$, frequency of attacks of migraine $(p<0.001$ and $P=0.001)$, duration of migraine attacks $(p=0.004$ and $p<0.001)$, and level of disability measured by MIDAS $(p<0.001$ and $P<0.001)$ respectively. However, they showed non-significant correlation with the age of patients or severity of pain according to VAS scores, based on statistical computations. On the other hand, serum calcium level showed only a statistically significant positive correlation with BMI $(p=0.007)$, with

Table 3 The severity of migraine and the level of impairment in daily activities were assessed by MIGSEV and MIDAS questionnaire

\begin{tabular}{|c|c|c|c|c|}
\hline \multirow[t]{2}{*}{ Questionnaire } & & & \multicolumn{2}{|c|}{ Patients' numbers } \\
\hline & & & Numbers & $\%$ \\
\hline \multirow[t]{18}{*}{ MIGSEV questionnaire } & Intensity of pain & Mild & 4 & $6.7 \%$ \\
\hline & & Moderate & 28 & $46.7 \%$ \\
\hline & & Intense & 28 & $46.7 \%$ \\
\hline & & very intense & 0 & $0.0 \%$ \\
\hline & Nausea & None & 12 & $20.0 \%$ \\
\hline & & Mild & 34 & $56.7 \%$ \\
\hline & & Intense & 14 & $23.3 \%$ \\
\hline & & Vomiting & 0 & $0.0 \%$ \\
\hline & Disability in daily activities & No & 16 & $26.7 \%$ \\
\hline & & Mild & 28 & $46.7 \%$ \\
\hline & & Marked & 16 & $26.7 \%$ \\
\hline & & Confined to bed & 0 & $0.0 \%$ \\
\hline & Tolerability & Tolerable & 22 & $36.7 \%$ \\
\hline & & barely tolerable & 22 & $36.7 \%$ \\
\hline & & Intolerable & 16 & $26.7 \%$ \\
\hline & MIGSEV Score & Grade 1 (low) & 26 & $43.3 \%$ \\
\hline & & Grade 2 (intermediate) & 24 & $40.0 \%$ \\
\hline & & Grade 3 (high) & 10 & $16.7 \%$ \\
\hline \multirow[t]{4}{*}{ MIDAS questionnaire } & Little or no disability & $(0-5)$ & 16 & $26.7 \%$ \\
\hline & Mild disability & $(6-12)$ & 28 & $46.7 \%$ \\
\hline & Moderate disability & $(11-12)$ & 14 & $23.3 \%$ \\
\hline & Severe disability & $(+21)$ & 2 & $3.3 \%$ \\
\hline
\end{tabular}

$\%$ percentage, MIGSEV migraine severity questionnaire, MIDAS Migraine Disability Assessment 


\section{Migraine Control}

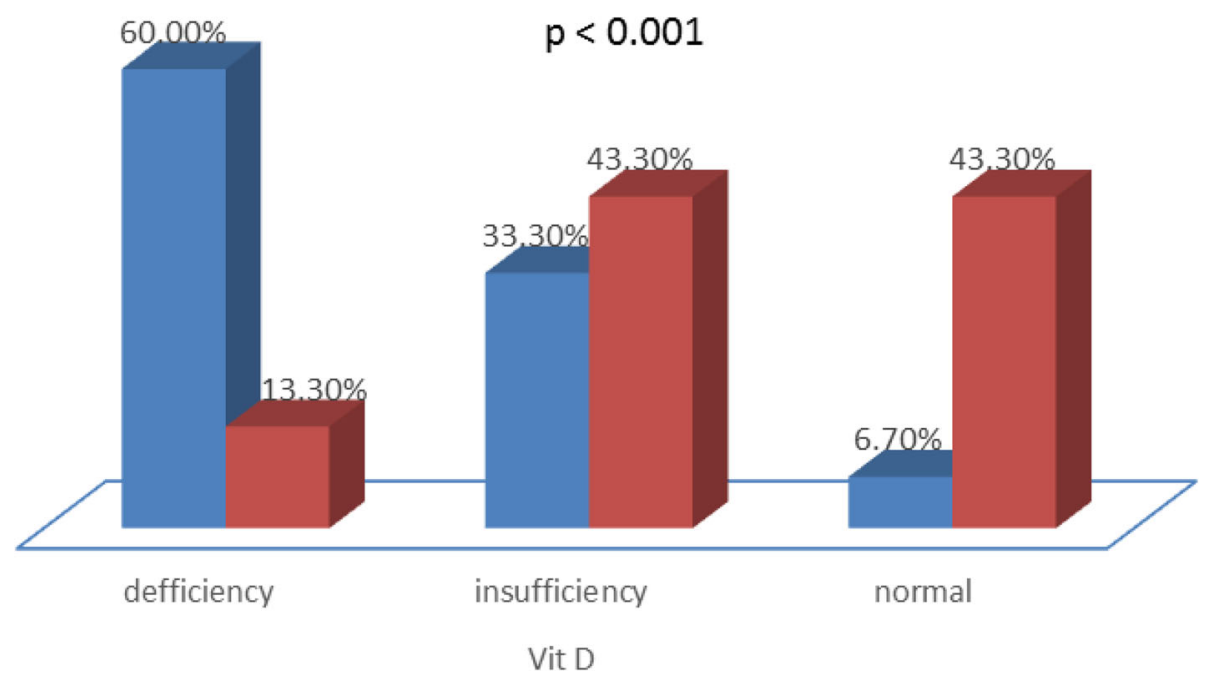

Fig. 2 Demonstration of vitamin D deficiency and insufficiency among migraineurs and healthy subjects

no statistically significant correlation with age of patients, frequency, duration, the severity of migraine, or level of disability by MIDAS. Vitamin D and serum magnesium levels showed a significant negative correlation with the severity of migraine assessed by the MIGSEV score $(p<$ 0.001 and $p<0.001$ respectively). Calcium also showed a negative correlation; however, there was no statistical significance (Table 6).

\section{Discussion}

Migraine should be viewed as a complex brain network disorder with a strong genetic basis that involves multiple cortical, subcortical, and brain stem regions, to account for the pain and the wide constellation of symptoms characterizing the disease [13]. Multiple pathological changes contribute to the origin of migraine

Table 4 Basic laboratory investigations and serum electrolytes of migraine patients and control

\begin{tabular}{llll}
\hline & $\begin{array}{l}\text { Migraine patients } \\
\text { Mean } \pm \mathrm{SD}\end{array}$ & $\begin{array}{l}\text { Control group } \\
\text { Mean } \pm \mathrm{SD}\end{array}$ & p value \\
\hline WBCs $\left(\times 10^{3} / \mathrm{cmm}\right)$ & $8.44 \pm 2.7$ & $6.35 \pm 3.1$ & 0.100 \\
RBCs $(/ \mathrm{million})$ & $4.8 \pm 0.5$ & $5.1 \pm 0.3$ & 0.080 \\
Platelets $\left(\times 10^{3} / \mathrm{cmm}\right)$ & $263.7 \pm 94$ & $211.4 \pm 57$ & 0.090 \\
HB $(\mathrm{g} / \mathrm{dL})$ & $12.4 \pm 3.3$ & $11.9 \pm 2.6$ & 0.210 \\
ESR $(\mathrm{mm} / \mathrm{h})$ & $18.5 \pm 13.5$ & $8.5 \pm 11.3$ & 0.075 \\
Total calcium $(\mathrm{mg} / \mathrm{dL})$ & $9.58 \pm 0.59$ & $9.31 \pm 0.45$ & 0.62 \\
Magnesium $(\mathrm{mEq} / \mathrm{L})$ & $1.88 \pm 0.20$ & $2.21 \pm 0.40$ & $\mathbf{0 . 0 4 1 *}$ \\
\hline
\end{tabular}

WBCs white blood cells, $R B C$ red blood cells, $H B$ hemoglobin, ESR erythrocyte sedimentation rate, $S D$ standard deviation

*Significant pain. Considerable circumstantial evidence suggests neuro-inflammation in the intracranial meninges to be a key element responsible for the sensitization of trigeminal meningeal nociceptors in migraine [14].

The anti-inflammatory effect of vitamin $\mathrm{D}$ is well documented, and several studies have shown that vitamin $\mathrm{D}$, at physiologic levels, can suppress the production of pro-inflammatory cytokines in human monocytes and macrophages [15].

The aim of this case-control study was to assess the serum level of vitamin D and its related minerals (calcium and magnesium) in patients with migraine and to evaluate its relation to the disease activity.

Our results confirmed the female predominance in migraine, where the female-to-male ratio was 2 to 1 . This high female-to-male ratio was reported in several studies [16, 17].

Our study basically provides information on the association between serum vitamin $\mathrm{D}$ and migraine. We have demonstrated that migraine sufferers have significantly lower vitamin $\mathrm{D}$ levels compared to the healthy subjects $(p<0.001)$. In our patients, the prevalence of vitamin D was $60 \%$ deficiency, $33.3 \%$ insufficiency, and only $6.7 \%$ normal. This observation is in accordance with a crosssectional prospective study conducted by Celikbilek and colleagues [18], where serum vitamin D levels were significantly lower in 52 newly diagnosed migraine patients than in controls $(p=0.012)$. In another prospective study conducted over 134 migraine patients in Italy, migraine sufferers had a severe vitamin D deficiency compared to the healthy subjects [19]. In Iran, Togha and colleagues [20] recruited seventy migraine patients and 
Table 5 Relation between vitamin D, calcium, and magnesium and migraine patient sub-groups

\begin{tabular}{|c|c|c|c|c|c|c|c|}
\hline & & \multicolumn{2}{|c|}{ Vitamin D level (ng/mL) } & \multicolumn{2}{|c|}{ Calcium (mg/dL) } & \multicolumn{2}{|c|}{ Magnesium (mEq/L) } \\
\hline & & Mean \pm SD & $p$ value & Mean \pm SD & $p$ value & Mean \pm SD & $p$ value \\
\hline \multirow[t]{2}{*}{ Aura } & Without & $\begin{array}{l}15.44 \pm 7.03 \\
(4-31)\end{array}$ & $0.002^{*}$ & $\begin{array}{l}9.51 \pm 0.58 \\
(8.70-10.50)\end{array}$ & $0.03^{*}$ & $\begin{array}{l}1.86 \pm 0.21 \\
(1.50-2.20)\end{array}$ & 0.11 \\
\hline & With & $\begin{array}{l}23.40 \pm 6.17 \\
(15-33)\end{array}$ & & $\begin{array}{l}9.94 \pm 0.53 \\
(9-10.50)\end{array}$ & & $\begin{array}{l}1.98 \pm 0.08 \\
(1.90-2.10)\end{array}$ & \\
\hline \multirow[t]{2}{*}{ Type of migraine } & EM & $\begin{array}{l}20.58 \pm 6.01 \\
(9-33)\end{array}$ & $<0.001 *$ & $\begin{array}{l}9.55 \pm 0.60 \\
(8.7-10.5)\end{array}$ & 0.12 & $\begin{array}{l}1.98 \pm 0.12 \\
(1.7-2.2)\end{array}$ & $0.04^{*}$ \\
\hline & CM & $\begin{array}{l}10.18 \pm 4.62 \\
(4-21)\end{array}$ & & $\begin{array}{l}9.61 \pm 0.60 \\
(8.8-10.5)\end{array}$ & & $\begin{array}{l}1.68 \pm 0.14 \\
(1.5-2)\end{array}$ & \\
\hline \multirow[t]{2}{*}{ Prophylaxis treatment } & yes & $\begin{array}{l}16.38 \pm 8.20 \\
(7-33)\end{array}$ & 0.650 & $\begin{array}{l}9.63 \pm 0.55 \\
(8.80-10.30)\end{array}$ & 0.67 & $\begin{array}{l}1.83 \pm 0.20 \\
(1.60-2.10)\end{array}$ & 0.17 \\
\hline & no & $\begin{array}{l}17.03 \pm 7.05 \\
(4-31)\end{array}$ & & $\begin{array}{l}9.54 \pm 0.62 \\
(8.70-10.50)\end{array}$ & & $\begin{array}{l}1.91 \pm 0.19 \\
(1.50-2.20)\end{array}$ & \\
\hline
\end{tabular}

EM episodic migraine, $C M$ chronic migraine, $S D$ standard deviation *Significant

found that they significantly had a lower mean of serum vitamin $\mathrm{D}(30 \pm 16 \mathrm{ng} / \mathrm{mL})$ than healthy subjects $(43 \pm$ $19 \mathrm{ng} / \mathrm{mL})(p<0.001)$. In addition, a higher level of serum Vitamin D (between 50 to less than $100 \mathrm{ng} / \mathrm{mL}$ ) is associated with $80-83 \%$ lower odds of migraine headache than those with serum $25(\mathrm{OH}) \mathrm{D}$ levels below 20 $\mathrm{ng} / \mathrm{mL}$. Vitamin D supplements can decrease inflammatory markers like C-reactive protein (CRP) which can suppress the neurogenic inflammation in migraine pathogenesis [21]. Vitamin D has a protective efficacy against endothelial dysfunction and this could explain the inverse relationship between nitric oxide $(\mathrm{NO})$ and $25(\mathrm{OH}) \mathrm{D}$ levels [22]. Elevated level of NO could lead to vasodilation [23] and elevate calcitonin gene-related peptide and substance $\mathrm{P}$ synthesis that ultimately may result in triggering nociceptive neurons and inflammation especially in trigeminovascular system [24].
Contrarily, Zandifar and colleagues [25] showed no significant differences in serum levels of vitamin $\mathrm{D}$ between cases and controls. However, they considered vitamin D sufficiency if it was $>20 \mathrm{ng} / \mathrm{mL}$. Furthermore, Kjaergaard and colleagues [26] were only able to detect a significant relationship between serum vitamin $\mathrm{D}$ and the types of headaches other than migraines. These differences might be presumably due to differences in race or residence area and study design.

Vitamin D insufficiency is not an unusual finding in our country, Egypt [27]. Although being a sunny country, these findings might be explained by inadequate dietary intake and inadequate sun exposure, probably due to cultural factors like veiling [28]. Also, darker skin, like most Egyptians, needs much longer time for sun exposure than that needed by fair skin to produce adequate vitamin $\mathrm{D}$ due to the higher amount of cutaneous melanin in darker

Table 6 Correlation of data of patients and headache character with Vitamin D, calcium, and magnesium serum level

\begin{tabular}{|c|c|c|c|c|c|c|}
\hline & \multicolumn{2}{|c|}{ Vitamin D level } & \multicolumn{2}{|l|}{ Calcium } & \multicolumn{2}{|c|}{ Magnesium } \\
\hline & $r$ value & $p$ value & $r$ value & $p$ value & $r$ value & $p$ value \\
\hline Age & -0.052 & 0.69 & 0.180 & 0.17 & -0.082 & 0.53 \\
\hline $\mathrm{BMI}$ & -0.475 & $<0.001^{*}$ & 0.348 & $0.007^{*}$ & -0.307 & $0.017^{*}$ \\
\hline Frequency of attacks & -0.70 & $<0.001^{*}$ & -0.546 & -0.55 & -0.546 & $<0.001^{*}$ \\
\hline Duration of attacks & -0.363 & $0.004^{*}$ & -0.244 & 0.06 & -0.533 & $<0.001^{*}$ \\
\hline VAS & -0.174 & 0.18 & 0.152 & 0.25 & -0.149 & 0.26 \\
\hline Level of disability on MIDAS & -0.51 & $0.001 *$ & 0.115 & 0.38 & -0.552 & $<0.001^{*}$ \\
\hline \multicolumn{7}{|l|}{ MIGSEV questionnaire } \\
\hline Intensity of pain & -0.17 & 0.21 & -0.25 & 0.05 & 0.16 & 0.23 \\
\hline Nausea & -0.14 & 0.29 & -0.09 & 0.45 & -0.34 & $0.007^{*}$ \\
\hline Disability in daily activities & -0.49 & $<0.001 *$ & 0.12 & 0.35 & -0.54 & $<0.001^{*}$ \\
\hline Tolerability & -0.55 & $<0.001^{*}$ & -0.24 & 0.07 & -0.52 & $<0.001^{*}$ \\
\hline MIGSEV (total score) & -0.56 & $<0.001^{*}$ & -0.17 & 0.21 & -0.51 & $<0.001^{*}$ \\
\hline
\end{tabular}

$B M I$ body mass index, VAS visual analogue scale, MIGSEV migraine severity questionnaire, MIDAS Migraine Disability Assessment *Significant 
pigmented skin, which slows the conversion to cholecalciferol in the skin [29].

We also showed that serum magnesium level was lower in migraine patients than in healthy controls, and our results are consistent with those of various other studies [30, 31]. Magnesium, specifically, plays a crucial role in the synthesis and metabolism of vitamin D. Also, intestinal absorption of magnesium is dependent on vitamin D. Hence, lower levels of vitamin D are generally associated with lower serum magnesium levels [32]. Assarzadegana and colleagues [33] in a case-control study showed that a sub-normal magnesium serum level increases the odds of a migraine attack up to 35 -fold. It has been suggested that magnesium plays a role in the pathogenesis of migraine by counteracting vasospasm, inhibiting platelet aggregation, and cell membrane stabilization [34]. Magnesium deficiencies could contribute to a modified mitochondrial metabolism by altering oxidative phosphorylation and neuronal polarization resulting in cortical spreading depression [35]. Magnesium also might be involved in the control of vascular tone and reactivity to neurotransmitter and endogenous hormones through plugging the N-methyl-D-aspartate (NMDA) receptor and preventing calcium from entering the cell and exert its effects on neurons and cerebral vascular muscles. NMDA receptors may play pivotal role in nociceptive processes, resulting in neuro-plastic changes in the trigeminal nociceptive neurons. Thus, NMDA receptor antagonists may be useful as an analgesic in the treatment of persistent pain [36].

Dissimilar to Yin and colleagues [37], we did not find any significant correlation between serum calcium level and any headache-related variables in migraine patients.

In contrast to Celikbilek and colleagues [18] and Togha and colleagues [20], our research showed significantly low levels of vitamin D in migraine without aura patients, rather than migraine with aura. However, magnesium level was not significantly different in migraine patients with aura and without aura. Our results here go in the same line with those of Talebi and colleagues [38].

We also observed a significant decrease in the serum levels of vitamin D and magnesium among chronic than episodic migraineurs. We found a significant inverse correlation between the frequency of migraine headache attacks and serum levels of vitamin D and magnesium. This was in agreement with a previous study conducted by Song and colleagues [39] in South Korea, where they found that vitamin D deficiency was present in $77.1 \%$ of patients, and that the duration of headache was related to the degree of vitamin $\mathrm{D}$ deficiency among migraineurs. Low vitamin $\mathrm{D}$ serum level is associated with a high incidence of chronic pain and headache [26]. Wheeler [40] reported that 14.8\% of patients with chronic migraine had serum vitamin D level $<20 \mathrm{ng} / \mathrm{mL}$, and $25.9 \%$ of them had serum vitamin D level between 20 and $30 \mathrm{ng} / \mathrm{mL}$. Talebi and colleagues [38] reported a significant linear relationship between the frequency of headaches and serum magnesium levels. These studies were in line with the findings of the present study.

In our study, there was a significant relationship between vitamin $\mathrm{D}$ and serum magnesium levels with migraine severity as assessed by the migraine severity questionnaire (MIGSEV). They both showed a significant inverse correlation with the MIGSEV questionnaire score especially "tolerability of pain" and "disability in daily activities" items. However, the "intensity of pain" item within the MIGSEV questionnaire or as assessed by the VAS scale showed no significant correlation with the levels of vitamin D and magnesium. Our results were in accordance with Song and colleagues [39] where they reported no significant difference in pain intensity on VAS and vitamin D level.

In a similar prospect, we showed that low vitamin D level is also linked to the degree of disability in daily activities in migraine patients as measured by the MIDAS scale, with a significant negative correlation between them. This is in agreement with the works of Rapisarda and colleagues [19]. Contrasting results were observed by Togha and colleagues [20], as they failed to find any correlation between vitamin D level and the MIDAS score.

Huang and colleagues [41] in a prospective case series of patients with chronic pain, who received 3 months of vitamin $\mathrm{D}$ supplementation, reported a significant decrease in the number of pain areas and in use of analgesics with improvement in sleep and quality of life, providing a more comprehensive evaluation of pain. Similarly, ThysJacobs [42] reported a dramatic reduction in frequency and duration of headaches after supplementation with vitamin D. Significant reduction in the intensity of photophobia and phonophobia was also observed in patients after receiving magnesium supplements [43].

Among all socio-demographic characteristics, we found a significant negative correlation of vitamin $\mathrm{D}$ level with body mass index (BMI), with a $p$ value $<0.001$. This result is in line with the works of Wortsman and colleagues [44] and Das and colleagues [45] who demonstrated that low serum levels of vitamin D have consistently been associated with higher adiposity represented in high BMI, as adipose tissue sequesters vitamin $\mathrm{D}$.

In the present study, we found that BMI had a significant positive correlation with calcium and inversely a significant correlation with magnesium serum level. These findings are in context with Ekweogu and colleagues [46]. The proposed mechanism is that low serum magnesium can increase weight gain by enhancing intracellular $\mathrm{Ca}^{+2}$ [47]. Increased $\mathrm{Ca}^{+2}$ in adipocytes activates phosphodiesterase-3B which decreases lipolysis [48] and enhances lipogenesis [49]. In addition, inflammatory cytokines that are produced by adipose tissue, especially TNF, enhance renal $\mathrm{Ca}^{+2}$ reabsorption and magnesium urinary excretions [50]. 
In spite of these results, our study has some limitations. First, the severity and disability scales and questionnaires used in our study were self-reported by the patients, and although we offered easy translations and clarified vague questions; however, the validity and reliability of their answers are questionable. Second, we did not control some comorbidities of migraine that may influence levels of vitamin $\mathrm{D}$, such as anxiety or depression.

\section{Conclusion}

The serum levels of vitamin D and magnesium are lower in migraine patients than in the control. The serum level of vitamin D and magnesium is linked to the frequency and tolerability of the headache attacks rather than the mere intensity of pain. Further, prospective large studies are essential to establish high-quality evidence for using vitamin $\mathrm{D}$ and/or magnesium supplements in the treatment of migraine.

\section{Acknowledgements}

The authors would like to appreciate all participants and their families as well as the hospital staff who contributed to the study.

\section{Authors' contributions \\ Elsayed DA, Amin KS, Elsayed IA, and Hashim NA carried out this work. Elsayed DA designed the study and had done the statistical analysis. Amin KS, Hashim NA, and Elsayed IA collected the patients, gathered clinical data, and wrote the manuscript. All authors were involved in drafting the article or revising it critically for important intellectual content, and all authors read and approved the final version to be published.}

\section{Funding}

This study was not supported by any source of finding

\section{Availability of data and materials}

Data and materials supporting the results of this article are included within the article (and its additional file(s)).

\section{Ethics approval and consent to participate}

The study was approved from the Institutional Ethics Committee of the Faculty of Medicine, Zagazig University (ZU-IRB \#4511/4-2018). Written informed consent was obtained from all study participants after explaining the details and benefits as well as risks to them. Surrogate consent from the patient's legal guardian or designated health proxy was permitted in cases where the patient did not have decision-making capacity.

\section{Consent for publication}

Not applicable.

\section{Competing interests}

The authors declared that they have no conflicts of interest with respect to the authorship and/or publication of this article.

\section{Author details}

${ }^{1}$ Department of Neurology, Faculty of Medicine, Zagazig University, Zagazig, Egypt. ${ }^{2}$ Department of Neuropsychiatry, Port-Fouad General Hospital, Port fouad, Egypt.

Received: 9 January 2020 Accepted: 6 April 2020

Published online: 01 May 2020

\section{References}

1. Ambrosini A, Coppola G. Pathophysiology of headaches. Molecule to Man. Switzerland. Springer Publications. 2015:155-68.
2. Puledda F, Messina R, and Peter J. Goadsby PJ. An update on migraine: current understanding and future directions. J Neurol. 2017; 264(9): 20312039

3. Kesby JP, Eyles DW, Burne TH, McGrath JJ. The effects of vitamin D on brain development and adult brain function. Mol Cell Endocrinol. 2011;347(2): $121-7$.

4. Rude RK, Adams JS, Ryzen E, Endres DB, Niimi H, Horst RL, et al. Low serum concentrations of 1,25-dihydroxyvitamin $D$ in human magnesium deficiency. J Clin Endocrinol Metab. 1985;61:933-40.

5. Swaminathan R. Magnesium metabolism and its disorders. Clin Biochem Rev. 2003;24(2):47-66.

6. Risco F, Traba ML. Possible involvement of a magnesium dependent mitochondrial alkaline phosphatase in the regulation of the 25 hydroxyvitamin D3-1 alpha-and 25-hydroxyvitamin D3-24R-hydroxylases in LLC-PK1 cells. Magnes Res. 1994:169-78.

7. Mauskop A, Altura B. Role of magnesium in the pathogenesis and treatment of migraines. Clin Neurosci. 1998;5(1):24-7.

8. Headache Classification Committee of the International Headache Society (IHS). The international classification of headache disorders, 3rd edition. Cephalalgia. 2018; 38(1):1-211.

9. McCormack HM, Horne DJ, Sheather S. Clinical applications of visual analogue scales: a critical review. PsycholMed. 1988;18:1007-19.

10. El Hasnaoui A, Vray M, Richard A, Nachit-Ouinekh F, Boureau F. MIGSEV Group. Assessing the severity of migraine: development of the MIGSEV scale. Headache. 2003;43(6):628-35.

11. Holick MF. The vitamin D deficiency pandemic: approaches for diagnosis, treatment and prevention. Rev Endocr Metab Disord. 2017; 18(2):153-65.

12. Levesque R. SPSS programming and data management: a guide for SPSS and SAS users (4th ed.).2007; Chicago, Illinois: SPSS Inc. ISBN 1-56827-390-8.

13. Puledda F, Messina R, Goadsby PJ. An update on migraine: current understanding and future directions. J Neurol. 2017:264(9):2031-9.

14. Goadsby PJ, Holland PR, Martins-Oliveira M, Hoffmann J, Schankin C, Akerman S. Pathophysiology of migraine: a disorder of sensory processing. Physiol Rev. 2017;97(2):553-622.

15. Ponsonby AL, McMichael A, Van Der Mei I. Ultraviolet radiation and autoimmune disease: insights from epidemiological research. Toxicology. 2002;181:71-8.

16. Lipton RB, Bigal ME, Diamond M, Freitag F, Reed ML, Stewart WF, et al. Migraine prevalence, disease burden, and the need for preventive therapy. Neurology. 2007;68(5):343-9.

17. Smitherman TA, Burch R, Sheikh H, Loder E. The prevalence, impact, and treatment of migraine and severe headaches in the United States: a review of statistics from national surveillance studies. Headache. 2013; 53(3):427-36

18. Celikbilek A, Gocmen AY, Zararsiz G, Tanik N, Ak H, Borekci E, Delibas N. Serum levels of vitamin D, vitamin D-binding protein and vitamin D receptor in migraine patients from central Anatolia region. Int J Clin Pract. 2014:68(10):1272-7.

19. Rapisarda L, Mazza MR, Tosto F, Gambardella A, Bono F, Sarica A. Relationship between severity of migraine and vitamin $D$ deficiency: a casecontrol study. Neurol Sci. 2018;39(Suppl 1):167-8.

20. Togha M, Razeghi Jahromi S, Ghorbani Z, Martami F, Seifishahpar M. Serum vitamin $D$ status in a group of migraine patients compared with healthy controls: a case-control study. Headache. 2018:58(10):1530-40.

21. Mottaghi T, Askari G, Khorvash F, Maracy MR. Effect of Vitamin D supplementation on symptoms and C-reactive protein in migraine patients. J Res Med Sci. 2015;20(5):477-82

22. Al-Daghri NM, Bukhari I, Yakout SM, Sabico S, Khattak MNK. Aziz I, et al Associations of serum nitric oxide with vitamin $D$ and other metabolic factors in apparently healthy adolescents. Biomed Res Int. 2018;2018:1489132.

23. lyengar S, Johnson KW, Ossipov MH, Aurora SK. CGRP and the trigeminal system in migraine. Headache. 2019;59(5):659-81.

24. Edvinsson L. The trigeminovascular pathway: role of CGRP and CGRP receptors in migraine. Headache. 2017:57(Suppl 2):47-55.

25. Zandifar A, Masjedi SS, Banihashemi M, Asgari F, Manouchehri N, Ebrahimi $\mathrm{H}$, et al. Vitamin D status in migraine patients: a case-control study. Biomed Res Int. 2014;2014:514782.

26. Kjergaard M, Eggen AE, Mathiesen EB, Jorde R. Association between headache and serum 25-Hydroxyvitamin D; the tromsø study: troms $\varnothing 6$ Headache. 2012;52(10):1499-505. 
27. Botros RM, Sabry IM, Abdelbaky RS, Eid YM, Nasr MS. Hendawy LM Vitamin D deficiency among healthy Egyptian females. Endocrinol Nutr. 2015;62(7): 314-21.

28. Amr N, Hamid A, Sheta M, Elsedfy H. Vitamin D status in healthy Egyptian adolescent girls. Georgian Med News. 2012;210:65-71.

29. Webb AR, Engelsen O. Calculated ultraviolet exposure levels for a healthy vitamin D status. Photochem Photobiol. 2006;82(6):1697-703.

30. Masoud A. A study on relation between attacks of migraine headache and serum-magnesium level. Iran J Public Health. 2003:27-30.

31. Samaie A, Asghari N, Ghorbani R, Arda J. Blood magnesium levels in migraineurs within and between the headache attacks: a case control study. Pan Afr Med J. 2012; 11(1)

32. Prakash S, Shah ND. Chronic tension-type headache with vitamin D deficiency: casual or causal association? Headache. 2009:49(8):1214-22.

33. Assarzadegan F, Asgarzadeh S, Hatamabadi HR, Shahrami A, Tabatabaey A, Asgarzadeh M. Serum concentration of magnesium as an independent risk factor in migraine attacks: a matched case-control study and review of the literature. Int Clin Psychopharmacol. 2016;31(5):287-92.

34. McCarty MF. Magnesium taurate and fish oil for prevention of migraine. Med Hypotheses. 1996;47(6):461-6.

35. Welch KMA, Ramadan NM. Mitochondria, magnesium and migraine. J Neurol Sci. 1995;134(1-2):9-14.

36. Sun-Edelstein C, Mauskop A. Role of magnesium in the pathogenesis and treatment of migraine. Expert Rev Neurother. 2009;9(3):369-79.

37. Yin P, Anttila V, Siewert KM, Palotie A, Davey Smith G, Voight BF. Serum calcium and risk of migraine: a Mendelian randomization study. Hum Mol Genet. 2017;26(4):820-8.

38. Talebi M, Savadi-Oskouei D, Farhoudi M, Mohammadzade S, Ghaemmaghamihezaveh S, Hasani A, et al. Relation between serum magnesium level and migraine attacks. Neurosciences (Riyadh). 2011;16(4): 320-3.

39. Song TJ, Chu MK, Sohn JH, Ahn HY, Lee SH, Cho SJ. Effect of vitamin D deficiency on the frequency of headaches in migraine. J Clin Neurol. 2018; 14(3):366-73.

40. Wheeler SD. Vitamin D deficiency in chronic migraine. Headache. 2008; 48(S1):S52-S53.

41. Huang W, Shah S, Long Q, Crankshaw AK, Tangpricha V. Improvement of pain, sleep, and quality of life in chronic pain patients with vitamin $D$ supplementation. Clin J Pain. 2013:29(4):341-7.

42. Thys-Jacobs S. Alleviation of migraines with therapeutic vitamin $D$ and calcium. Headache. 1994;34(10):590-2.

43. Bigal ME, Bordini CA, Tepper SJ, Speciali JG. Intravenous magnesium sulphate in the acute treatment of migraine without aura and migraine with aura. A randomized, double-blind, placebo-controlled study. Cephalalgia. 2002;22(5):345-53.

44. Wortsman J, Matsuoka LY, Chen TC, Lu Z, Holick MF. Decreased bioavailability of vitamin D in obesity. Am J Clin Nutr. 2000;72(3):690-3.

45. Das G, Crocombe S, McGrath M, Berry JL, Mughal MZ. Hypovitaminosis D among healthy adolescent girls attending an inner city school. Arch Dis Child. 2006;91(7):569-72.

46. Ekweogu CN, Egwurugwu JN, Ohamaeme MC, Ugwuezumba PC, Nwankpa P, Azudialu BC. Relationship between body mass index and serum calcium and magnesium in an adult population in Owerri. Nigeria. Niger J Exp Clin Biosc. 2018;6(1):13.

47. Draznin B, Sussman KE, Eckel RH, Kao M, Yost T, Sherman NA. Possible role of cytosolic free calcium concentrations in mediating insulin resistance of obesity and hyperinsulinemia. J Clin Invest. 1988;82(6):1848-52.

48. McCarty MF, Thomas CA. PTH excess may promote weight gain by impeding catecholamine-induced lipolysis-implications for the impact of calcium, vitamin D, and alcohol on body weight. Med Hypotheses. 2003; 61(5-6):535-42.

49. Shi H, DiRienzo D, Zemel MB. Effects of dietary calcium on adipocyte lipid metabolism and body weight regulation in energy-restricted aP2-agouti transgenic mice. FASEB J. 2001;15(2):291-3.

50. Alcock N, Maclntyre I. Inter-relation of calcium and magnesium absorption. Clin Sci. 1962:22:185-93.

\section{Publisher's Note}

Springer Nature remains neutral with regard to jurisdictional claims in published maps and institutional affiliations.

\section{Submit your manuscript to a SpringerOpen ${ }^{\circ}$ journal and benefit from:}

- Convenient online submission

- Rigorous peer review

- Open access: articles freely available online

- High visibility within the field

- Retaining the copyright to your article

Submit your next manuscript at $\boldsymbol{\nabla}$ springeropen.com 